\title{
Propulsion Vehicle Integration \\ For Reusable Launcher Using \\ In-flight Oxygen Collection
}

\author{
D. Bizzarri ${ }^{1}$, P. Hendrick ${ }^{1}$, G. Heyen ${ }^{2}$ \& P. Ngendakumana ${ }^{2}$ \\ ${ }^{1}$ University of Brussels, BELGIUM \\ ${ }^{2}$ University of Liège, BELGIUM
}

- Corresponding Author: D.Bizzarri, Université libre de Bruxelles CP165/43,Dpt of fluid Mechanics, Avenue F.Roosevelt 50, 1050 Brussels, Belgium. Tel + 326506654 . Fax + 3265027 10. Email Didier.Bizzarri@ulb.ac.be

\begin{abstract}
The use of in-flight Oxygen Collection has shown to significantly improve space launcher performance. The conceptual approach followed by Belgian teams working on oxygen collection has been to try to widening the available design margins in order to reduce the required technological leap and limit the economical risk associated with such a development. The aim of the ESA-funded theoretical and experimental study on an air separation device is to demonstrate the possibility of performing efficient air distillation in a compact rotating column. An integration of the vehicle, propulsion system and separation unit designs is presented. The objective is to optimise the overall vehicle performance while keeping technological difficulty and system complexity at a reasonable level.

Reference vehicles are presented within their specific mission profiles with an emphasis on TSTO's.

Different layouts of the internal energy and mass flowsheets have been studied and were compared in order to make best use of the refrigeration capacity of the hydrogen fuel running though the propulsion system during the first phase of the flight. In those flowsheets, the separator is considered as a classical distillation tray column. That analysis provides the requirements in terms of heat exchange capacity, compression ratios and number of so-called transfer units needed in the separator. The system is intentionally kept simple to limit complexity, but the analysis is thorough and accurate, including, for example, the effect of the presence of argon. Results for a supersonic carrier are presented.

A compact separation unit has been designed in order to reach those requirements. That includes internals, practical building with estimates of pressure drops, separation performance
\end{abstract}

Corresp. author : D.Bizzarri, Université libre de Bruxelles CP165/43,Dpt of fluid Mechanics, Avenue F.Roosevelt 50, 1050 Brussels, Belgium. Tel + 32650 6654. Fax + 326502710 .

Email Didier.Bizzarri@ulb.ac.be 
and flow limitation. Main results are given, sizing of the separator bed is provided for a carrier plane showing that such on-board separator is indeed practical.

\section{Nomenclature}

CR Collection ratio (mass of LEA produced per unit mass of $\mathrm{LH}_{2}$ consumed)

Cox Oxygen mass fraction in the flow (by default, in the LEA flow)

LCP LOX/LEA Collection Plant

LEA Liquefied (oxygen) Enriched Air

LEO Low Earth Orbit

$\mathrm{LH}_{2} \quad$ Liquid Hydrogen

$L O X \quad$ Liquid Oxygen

SSTO Single-Stage-To-Orbit

TOGW Take Off Gross Weight

TSTO Two-Stage-To-Orbit

\section{Introduction}

Belgium, since the mid 90's and with the help of a strong ESA support (FESTIP programs [1]), has been investigating the concept of a 2-stage launcher whose first stage is based on hydrogen fuelled turbofan engines and carries a second pure rocket orbital stage. The attractiveness of this design relies on the large reduction in total vehicle take-off weight provided by the ability to collect liquid oxygen for the second stage during flight. Since oxygen is the largest mass component of a rocket powered vehicle, oxygen collection technology, trajectory optimisation, and stage separation have been key technical points requiring definitive and practicable if not straightforward answers.

Two concepts of TSTO's using in-flight liquid oxygen (LOX) collection will be presented. In both cases the first stage of the launcher is a reusable air-breathing vehicle. In the first layout, separation is performed at a relatively high supersonic mach number whereas in the second, separation occurs at subsonic velocity. The second option with its subsonic separation does not provide a very significant delta $\mathrm{V}$ for the orbiter, however it provides other sensible advantages, i.e. a far easier realization in a near future and a larger flexibility of the solution concerning the orbit and the launch azimuth.

After the presentation of those two concepts, technology developments which started in Belgium a bit more than 2 years ago are explained.

\section{System studies}

\subsection{General Framework}

In Belgium, research activities on air-breathing and other advanced launchers conducted with universities started in 1994 together with a company called VDK Systems. The activities were mainly focussed on ram- \& scram simulations and vehicle sizing \& trajectory calculations. From 1996, with the support of the Belgian Space Delegation, a concentration of the activities on a particular topic has been clearly marked towards the Oxygen Collection Cycles and Vehicles (also sometimes called ACES for Air Collection \& Enrichment Systems). Three studies have been completed until now: first a Belgian funded ESA feasibility study, then a study on ACES SSTO's in FESTIP I and, finally, on ACES supersonic and subsonic staging

Corresp. author : D.Bizzarri, Université libre de Bruxelles CP165/43,Dpt of fluid Mechanics, Avenue F.Roosevelt 50, 1050 Brussels, Belgium. Tel + 32650 6654. Fax + 326502710 .

Email Didier.Bizzarri@ulb.ac.be 
TSTO's in FESTIP II. In FESTIP I \& II, experimental work has also been accomplished by the University of Liège on air separation through vortex tubes by the team of $\mathrm{Ph}$. Ngendakumana (figure 1).

Two examples of analysed launchers are shown hereafter.

\subsection{TSTO with supersonic collection case study}

The ACES TSTO with supersonic staging and collection at supersonic speed has been deeply studied by Techspace Aero (Prime Contractor), the follow-up of the VDK -hosted by the Belgian Royal Military Academy (RMA)- and the Von Karman Institute during the ESA Festip II program.

This in-flight LOX Collection concept has been the subject of studies and technology demonstrations since the 60's. It consists in collecting air during the atmospheric phase of a launch, enriching its oxygen content by separating and rejecting the nitrogen and storing the liquefied enriched air (nearly liquid oxygen) in the tanks for a subsequent rocket propulsion phase. Air pre-cooling and liquefaction are realized in heat exchangers thanks to the high cooling capacity of hydrogen fuel. This concept is here applied to a TSTO in a rather different way than what has been proposed by the USAF in the 60's and early 90 's.

With a staging (separation) Mach number between 4 and 5, it can provide a very interesting launcher solution, even if the collection phase takes place in cruise only, at a relatively "low" cruise Mach number (about 2.5) and with a "moderate" Collection Ratio (i.e. the ratio of collected LOX mass flow rate per kilo of hydrogen used in the launcher, e.g. $\mathrm{CR}=3$ or less, even though assumed values around 5 are frequently quoted in the literature). Indeed, the ACES TSTO concept allows to take-off with a much lighter vehicle (no LOX in the tanks) which induces a lighter landing gear, a lighter propulsion plant, a quicker climb phase (with less drag) and, last but not least, a lower planform area (Spf1), which means a lighter structure, for a given planform loading at take-off. The second stage can be reusable or expendable making the whole transportation system fully reusable or semi-reusable.

The launcher's $1^{\text {st }}$ stage is propelled by gas turbine engines from take-off up to Mach 3.8. It is followed by ramjet propulsion up to the staging Mach number (e.g. Mach 5.0). Three aspects of the launcher were studied : $1^{\text {st }}$ stage propulsion (von Karman Institute), LOX Collection Plant (LCP) pre-design (Techspace Aero) and integration of the results of these two studies in a pre-design tool used to evaluate the performance of such a launch vehicle (RMA) [2].

One of the challenges of this study is to integrate propulsion and LCP. Indeed the LCP requires an air intake, a compressor to overcome the high pressure losses in the heat exchangers and in the $\mathrm{N}_{2}-\mathrm{O}_{2}$ separator, and a nozzle to reject the oxygen depleted air and recover a part of the collection drag. As these elements are already present for the airbreathing propulsion of the first stage, an interesting idea is to integrate the LCP with the propulsion engines by using the bypass flow of a turbofan engine (LBPR) as the incoming air to the collection plant during the collection phase of the flight. The outer part of the LP compressor is also the LCP compressor. The depleted air is reintroduced into the bypass to be mixed with the engine core flow and expanded in the main nozzle with the possibility of afterburning. This is done to decrease the additional drag induced by LOX collection and reduce the total mass. The schematic of the system is shown in figure 2.

The feasibility of this original system has been analysed through cycle studies and performance analysis for design and off-design engine operation. Different engine configurations and LCP variants were investigated and their performance along the entire trajectory calculated. One difficulty is that the sub-systems and the vehicle studies interact

Corresp. author : D.Bizzarri, Université libre de Bruxelles CP165/43,Dpt of fluid Mechanics, Avenue F.Roosevelt 50, 1050 Brussels, Belgium. Tel + 32650 6654. Fax + 326502710 . Email Didier.Bizzarri@ulb.ac.be 
strongly with each other. For example, the hydrogen used in the LCP has to match the engine fuel consumption which is related to the required vehicle thrust. To design that advanced launcher, a vehicle sizing \& trajectory calculation tool such as the one developed at RMA [2] is absolutely required.

The iterations between TA, VKI and RMA lead to a vehicle whose front part of the turbofan engine had to be fitted with a ring pre-cooler system as sketched in figure 3 .

The first stage flies at a constant dynamic pressure trajectory of $43 \mathrm{kPa}$. Its mission is mainly an acceleration mission from take off to staging at Mach 5 although a cruise is needed at Mach 2.5. This cruise phase provides the necessary time for LOX collection and ensures a stable on-design operation of the LCP for a large part of the collection phase.

The turbo-engines must be used from take off to Mach 3.8 while ramjet propulsion ensures the final acceleration, the pull-up for separation and the first part of the return flight, before gliding. LOX collection can take place within the 1.8 to 3 Mach number range, including the cruise at Mach 2.5 or only in cruise. The total thrust capability of the 8 combined engines equipped with the ring pre-cooler system is given in figure 4 for stoichiometric reheat.

The thrust diminution during the LOX collection phase is due to the lower amount of oxygen available for afterburning and to the necessary throttle-down for the reduction of the LP compressor rotational speed.

Different options were also investigated for the location of the heat exchangers, including the calculation of the LCP performance. An option is sketched on figure 5.

The input parameters of the LCP thermodynamic calculations are adapted to the data provided by the propulsion plant study presented above. These data correspond to an 8 engines first stage launcher. The air processed through the LCP for each engine is approximately $50 \mathrm{~kg} / \mathrm{s}$ and the enriched air (LOX) production is about $8 \mathrm{~kg} / \mathrm{s}$. The main data provided by the propulsion study are the outer fan pressure ratio and the bypass air mass flow rate. An example of the LCP simulation is shown for a Mach 2.5 cruise collection phase on figure 6 . The most important result of this simulation is certainly the value of the collection ratio CR, here equal to $7.97 / 2.85$ or 2.8 .

The results of the sub-system detailed studies are then introduced in a pre-design vehiclesizing tool which integrates the propulsion, aerodynamics and in-flight LOX collection aspects using the results provided by the sub-system studies with a complete vehicle trajectory calculation and a mass $\&$ volume model of both stages.

Table 1 is for a fully reusable HTOHL (Horizontal Take-Off Horizontal Landing) TSTO staging at Mach 5.0 and a CR of 2.8. Collection takes place in acceleration (between Mach 1.8 and 3.0) but mainly in cruise (at Mach 2.5, $16.7 \mathrm{~km}$ altitude).

It is shown that, with a LOX purity of $90 \%$, the launch of a payload of 7 tonnes on an equatorial LEO (ESA FESTIP requirement) requires a TOGW as low as $370 \mathrm{t}$ with a $1^{\text {st }}$ stage dry mass of 200 tonnes for a fully reusable TSTO taking off from Kourou. In all these launch vehicles, the collection plant mass represents only less than $2 \%$ of the $1^{\text {st }}$ stage dry mass. The specific mass of the collection plant (and thus mainly of the different heat exchangers) is therefore not critical, like it is in a SSTO with in-flight LOX collection or in the USAF studies of the 60's and '80's $[3,4,5]$.

Corresp. author : D.Bizzarri, Université libre de Bruxelles CP165/43,Dpt of fluid Mechanics, Avenue F.Roosevelt 50, 1050 Brussels, Belgium. Tel + 32650 6654. Fax + 326502710 . Email Didier.Bizzarri@ulb.ac.be 


\subsection{TSTO with subsonic collection case study}

A subsonic air-launched ACES vehicle offers also very consequent advantages. Here, a part of the launcher is an orbiter which is in fact an all-rocket SSTO launcher taking off from about $10 \mathrm{~km}$ altitude and about 0.70 Mach.

This type of concept, comparable to the UK Interim HOTOL and the Russian MAKS, is considered with the use of In-Flight LOX Collection and a ventrally-launched expendable orbiter.

The TSTO launcher is composed of an all-rocket winged-body orbiter air-launched from the belly of a large subsonic carrier-plane (first stage or mothership) almost entirely built from structural elements available now on existing civil transport aircraft. This carrier-plane is a twin-fuselage airplane where the two large hydrogen tanks are derived from the fuselage of the Boeing 777-300 [6]. The LCP is located in one of the fuselage. LOX is collected at a low mass flow rate (e.g. $10 \mathrm{~kg} / \mathrm{s}$ ) during a long subsonic flight and stored in the underbelly $2^{\text {nd }}$ stage. The $1^{\text {st }}$ stage engines are four GE-90 type engines converted to burn hydrogen. The only new structural elements are two wings between the B777 fuselages plus probably an adapted wing box.

The main reason for the choice of the twin-fuselage design (figure 7) is, in our case, the space needed for the storage of the hydrogen fuel which is also used for the chilling down of the incoming air for the collection plant.

A rather detailed aerodynamic, structural and performance study of this B777-based

mothership has been performed by RMA.

\section{System analysis, the separation plant}

The structure of in-flight oxygen collection equipment has been studied using a mathematical model, in order to define suitable operating conditions and to assess the design sensitivity with respect to several criteria, such as the collection ratio or the oxygen purity.

The model is aimed at representing the steady state behaviour of the separation unit, and is based on the equilibrium stage assumption. It allows exploring the entire set of typical operating conditions, to help in the design of the experimental test bench, to study the process sensitivity with respect to command variables, and to help interpreting experimental results.

A property model has been first selected to reproduce physical and thermodynamic properties, as well as vapour-liquid equilibrium of $\mathrm{O}_{2}-\mathrm{N}_{2}$-Ar mixtures. We selected the Peng-Robinson equation of state [7] to predict vapour-liquid equilibrium and residual properties. Binary interaction parameters required to predict mixture properties were fitted to reproduce experimental data available in Knapp et al (1982) [8]. Different layout complexity and carrier options were investigated; we present here a rather effective solution for the supersonic carrier option.

\subsection{Supersonic case}

The simulation model comprises five heat exchangers, two compressors and one separator with 12 equilibrium stages (see figure 8)

The air feed is first cooled down in HX5 by hydrogen to be reheated before entering a combustor. It is then compressed, and cooled by depleted air in unit HX1. The air is later split into two streams: the main one is further cooled (close to its dew point) in unit HX2 by hydrogen, and it is fed to the separation unit. The secondary stream is compressed in order to raise its dew point temperature, and is condensed almost totally in the reboiler HX3 before entering the column at the same location as the main air stream. The separator produces LOX,

Corresp. author : D.Bizzarri, Université libre de Bruxelles CP165/43,Dpt of fluid Mechanics,

Avenue F.Roosevelt 50, 1050 Brussels, Belgium. Tel + 32650 6654. Fax + 326502710 .

Email Didier.Bizzarri@ulb.ac.be 
or more precisely liquid oxygen enriched air (LEA) which is partially reboiled to provide stripping gas to the separator; at the cold side, the condenser HX4, cooled by LH2, provides reflux to the system.

Main performance parameters have been investigated:

$\begin{array}{ll}\text { - } & \text { collection ratio }(\mathrm{kg} \text { LOX produced per } \mathrm{kg} \mathrm{H} \text { vaporized) } \\ \text { - } & \text { separation efficiency }\left(\mathrm{O}_{2} \text { in } \mathrm{LOX} / \mathrm{O}_{2} \text { in air feed }\right) \\ \text { - } & \text { mass fraction of } \mathrm{O}_{2} \text { in residual air } \\ & \text { mass fraction of } \mathrm{O}_{2} \text { in } \mathrm{LOX}\end{array}$

The study demonstrated that by an appropriate choice of the command variables, the net collection ratio ( $\mathrm{kg} \mathrm{O} 2$ in $\mathrm{LOX} / \mathrm{kg} \mathrm{H} 2$ used) can exceed 3 with a separation efficiency well above $75 \%$.

Oxygen purity target should not exceed 95\%, since exceeding this target would imply also removing Argon. Such a separation is much more difficult than the $\mathrm{N}_{2}-\mathrm{O}_{2}$ split, and requires a much larger distillation unit, and a higher reflux ratio.

The results of the air enrichment and collection plant steady state model are found satisfactory. A 12 equilibrium stages separator is sufficient to obtain Liquid Enriched Air of 95\% purity, which is more than sufficient and a collection ratio of 3 which is satisfactory for the supersonic reference vehicle and is very generous for the subsonic reference vehicle, which may accept a much lower collection ratio (down to 1). A detailed conclusion follows.

\section{Sizing of the separation unit}

The separator is the core of the enrichment process. Air enrichment uses the different volatilities of oxygen and nitrogen as it is done in distillation. Mass transfer is performed in a set of compact, rotating, high centrifugal acceleration devices that might either be separate or integrated on a single shaft and in such a case, either side by side or on top of each other.

Flow schematics of such a device, in its simplest form, can be seen on figure 9.

The device is essentially a high specific surface liquid-gas contactor, contact occurring by trickling the liquid on a porous material, the separator bed, thanks to high accelerations. A high porosity high specific surface bed material has been selected [9] and its performance studied. The material shows a porosity over $93 \%$ and a specific surface ranging from 500 to $5000 \mathrm{~m}^{2} / \mathrm{m}^{3}$.

The study shows that the sizing of the device is mainly based on two parameters, the maximum gaseous throughput and the height of a transfer unit -although to a lesser extent-, that is the depth of the bed that performs the work of an equilibrium stage. A full phenomenological study has been performed and allows performing a realistic preliminary sizing of the separator bed required. For practical reasons, we will consider here that the column is split into different contactors rather than putting everything on a single machine. The resulting throughput for a separator operating at 3 bara and under $200 \mathrm{~g}$ with a bed specific surface of $2500 \mathrm{~m}^{2} / \mathrm{m}^{3}$ is $13 \mathrm{~kg} / \mathrm{m}^{2} / \mathrm{s}$ in the stripping section and $16 \mathrm{~kg} / \mathrm{m}^{2} / \mathrm{s}$ in the rectification section. Since the rectifying section is more throughput critical and less demanding in terms of mass transfer, a coarser material is probably more adapted. Changing to coarser bed material for the rectifying section, with a specific surface of $1000 \mathrm{~m} 2 / \mathrm{m} 3$, the load point rises to $25 \mathrm{~kg} / \mathrm{m}^{2} / \mathrm{s}$. Doing so will allow to simplify the design of the separator and

Corresp. author : D.Bizzarri, Université libre de Bruxelles CP165/43,Dpt of fluid Mechanics, Avenue F.Roosevelt 50, 1050 Brussels, Belgium. Tel + 32650 6654. Fax + 326502710 . 
to follow a modular approach. After estimating the mass transport limitation, the sizing can be performed. The required LEA production for both subsonic and supersonic carrier concepts are taken from [9] (table 2).

\subsection{A modular design}

The route chosen here for the design exercise of the separator is modular. As quoted, the same unit will be used many times with only one modification: the specific surface of the separator bed. The clear aim is to reduce development cost and uncertainties. Such a design choice may divide the cost of the early supply of separators for a new growing fleet of vehicle by 2 or more, yet opening the way for different markets, well beyond space launch applications. Figure 10 shows the bed dimensions for the base unit with the subsonic carrier option. Use description and discussion follows.

\subsection{Subsonic case}

Considering only 3 of such units ( 2 rectification units +1 stripping unit) are required for the subsonic first stage version (not including the heat exchangers) which is surprisingly small. The bed alone of the base unit, would weight about $100 \mathrm{~kg}$. The complete base unit may weight several times this amount, depending much on the design choices and the construction efforts. Still, increasing the pressure would decrease the size of the system significantly and in any case, unit weight and volume are reasonable.

\subsection{Supersonic case}

In the supersonic case, about 20 base units would be required, which could become unpractical. For this reason, a different design could be studied. Increasing length may be the best solution. The base units would come out in elongated tubes shape suspended at their extremities on their supporting bearings. Making a second base unit 7 times longer, while keeping all other dimensions equal, would lead, as previously, to a three base unit separator for the supersonic case. The volume still seems reasonable for that type of vehicle although interaction with the airframe of the first stage becomes serious.

\section{Conclusions}

The in-flight oxygen collection concept has been applied to two TSTO options: a solution using high supersonic speed staging and another using subsonic staging and relying on a two fuselage air-breathing first stage or mothership. The latter solution offers interesting performance and the development suggest potential synergies with other applications, including in the industry.

The detailed study of the air enrichment and liquefaction plant shows that the realization appears feasible. System configurations have been analyzed for both the supersonic and the subsonic cases. System constraints and operating conditions have been identified, and a sensitivity analysis has been carried out.

Corresp. author : D.Bizzarri, Université libre de Bruxelles CP165/43,Dpt of fluid Mechanics, Avenue F.Roosevelt 50, 1050 Brussels, Belgium. Tel + 32650 6654. Fax + 326502710 . Email Didier.Bizzarri@ulb.ac.be 
It appears that, with a proper selection of command variables, all system targets could be met with a global 12 transfer (rectification+stripping) unit separator:

- LOX purity up to $95 \%$ weight;

- collection ratio up to 3;

- separation efficiency in a $75 \%$ range.

The model does not contain unrealistic hypothesis: irreversibilities in compression and heat transfer have allowed for. The only hypothesis that might be difficult to meet in practice is the perfect thermal insulation (no cooling losses) [10] which will increase the demand on the heat sink, liquid hydrogen.

The sizing of the unit shows the feasibility of the concept. Even though some computations, are necessarily approximate without experimental results, the overall design seem rather insensitive to the separator sizing assumptions, leaving very generous margins as well as great design freedom for the realization of separator/contactor units, at least in the subsonic carrier option.

Finally, although the first space vehicle using atmospheric oxygen capture and liquefaction is not just around the corner, new results make us more confident that the general concept, if properly applied, has huge potentials. It is shown to be a robust and promising route to new (reusable) launcher applications.

\section{References}

[1] P. Hendrick, F. Breugelmans, B. Marquet, M. Saint-Mard, M. Strengnart, P. Ngendakumana and D. Bizzarri, "Fully and Partially Reusable TSTO launchers using InFlight LOX Collection", ISTS 2000-g-09, Morioka, 28 May - 02 June 2000.

[2] P. Hendrick, "VPSC, a vehicle parametric sizing code", AIAA-2001-1846, Kyoto, 24 - 27 April 2001.

[3] Leingang J.L., Maurice L.Q. \& Carreiro L., Wright Laboratory, "In-Flight Oxidiser Collection Systems for Airbreathing Space Boosters", Developments in High-Speed-Vehicle Propulsion Systems, AIAA book, Vol. 165, Ch. 7, pp 333-384, 1996.

[4] Gottzmann C. et al., "Airborne Rotary Air Separator Study", Union Carbide Industrial Gases Inc., NASA CR-189099, Dec 1990.

[5] DRNEVICH R \& NOWOBILSKI J., "Airborne Rotary Air Separator Study", Praxair, NASA CR-191045, Dec 1992.

[6] P. Hendrick \& A. Mignon, "Utilization of Existing Large Subsonic Aircraft Elements to Implement In-Flight LOX Collection Aircraft", AIAA-2000-3107, JPC, Huntsville, 16-19 July 2000.

[7] Peng D.Y, Robinson D.B., "A new two-constant equation of state", Ind.Eng.Chem., Fundam. 15, 59-64 (1976).

[8] H. Knapp, R. Döring, L. Oellrich, U. Plöcker, J.M. Prausnitz, R. Langhorst, S. Zeck, "Vapor-Liquid Equilibria for Mixtures of Low Boiling Substances", Chemistry Data Series Vol 6, DECHEMA (1982).

[9] D. Bizzarri \& P. Hendrick, "Study and development of an air distillation subscale unit for in-flight oxygen collection", Proceedings of $12^{\text {th }}$ AIAA International Space Planes and Hypersonic Systems and Technologies, Norfolk, Virginia (2003).

[10] D. Bizzarri, G. Heyen, P. Hendrick, \& Ph. Ngendakumana, "Integration of Vehicle, Propulsion System and Separation Unit designs for a launcher using in-flight oxygen collection", Proceedings of $13^{\text {th }}$ AIAA International Space Planes and Hypersonic Systems and Technologies, Capua, Italy (2005).

Corresp. author : D.Bizzarri, Université libre de Bruxelles CP165/43,Dpt of fluid Mechanics, Avenue F.Roosevelt 50, 1050 Brussels, Belgium. Tel + 32650 6654. Fax + 326502710 .

Email Didier.Bizzarri@ulb.ac.be 
$\% \% \% \% \% \% \% \% \% \% \% \% \% \% \% \% \% \% \% \% \% \% \% \% \% \% \% \% \% \% \% \% \% \% \% \% \% \% \% \% \% \%$ $\% \% \% \% \% \% \% \% \%$

\section{FIGURES}

$\% \% \% \% \% \% \% \% \% \% \% \% \% \% \% \% \% \% \% \% \% \% \% \% \% \% \% \% \% \% \% \% \% \% \% \% \% \% \% \% \% \% \% \%$ $\% \% \% \% \% \% \% \% \%$

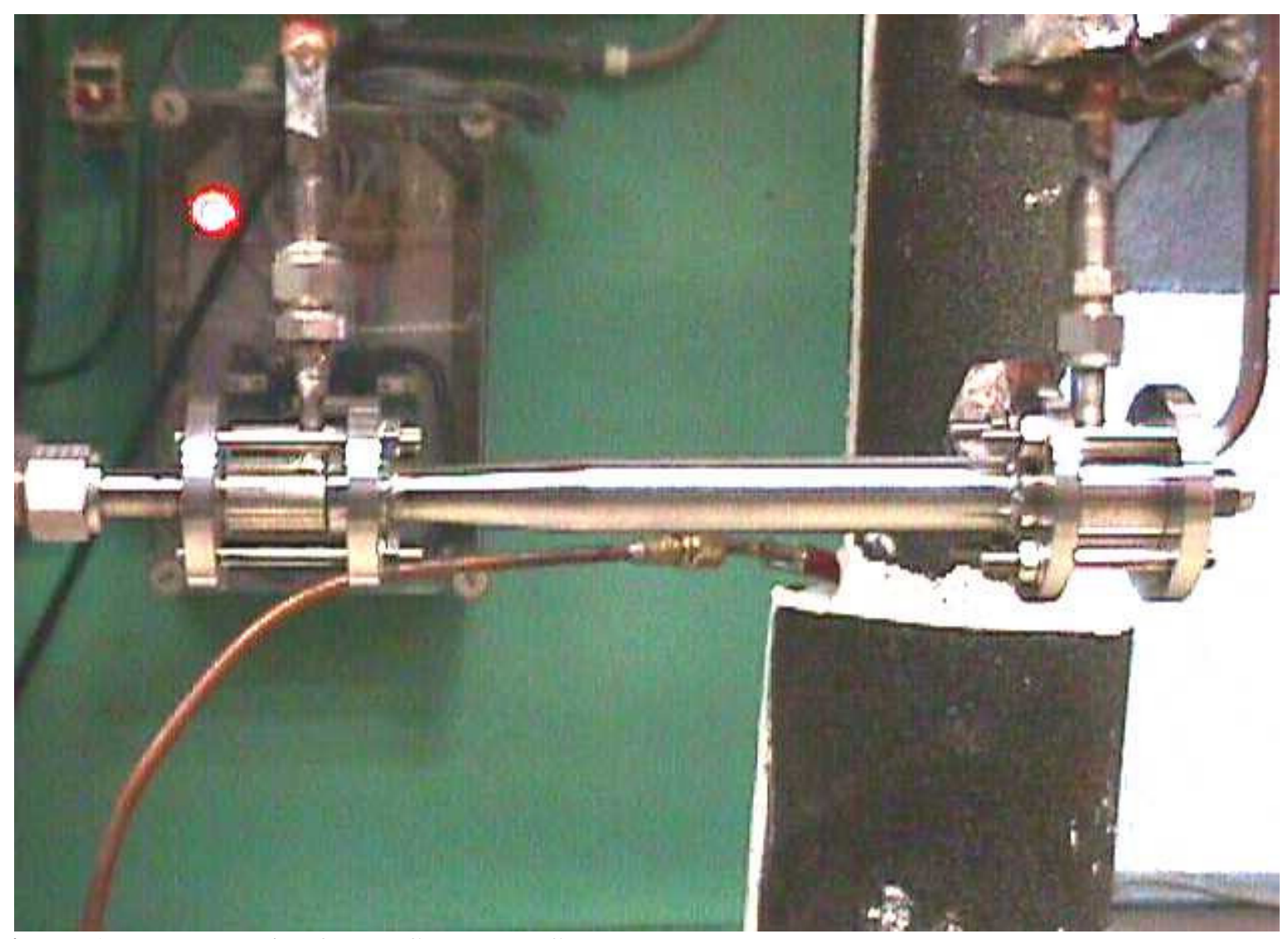

Figure 1: Vortex Tube $\mathrm{O}_{2}-\mathrm{N}_{2}$ Separator Set-Up

Corresp. author : D.Bizzarri, Université libre de Bruxelles CP165/43,Dpt of fluid Mechanics, Avenue F.Roosevelt 50, 1050 Brussels, Belgium. Tel + 32650 6654. Fax + 326502710 . Email Didier.Bizzarri@ulb.ac.be 


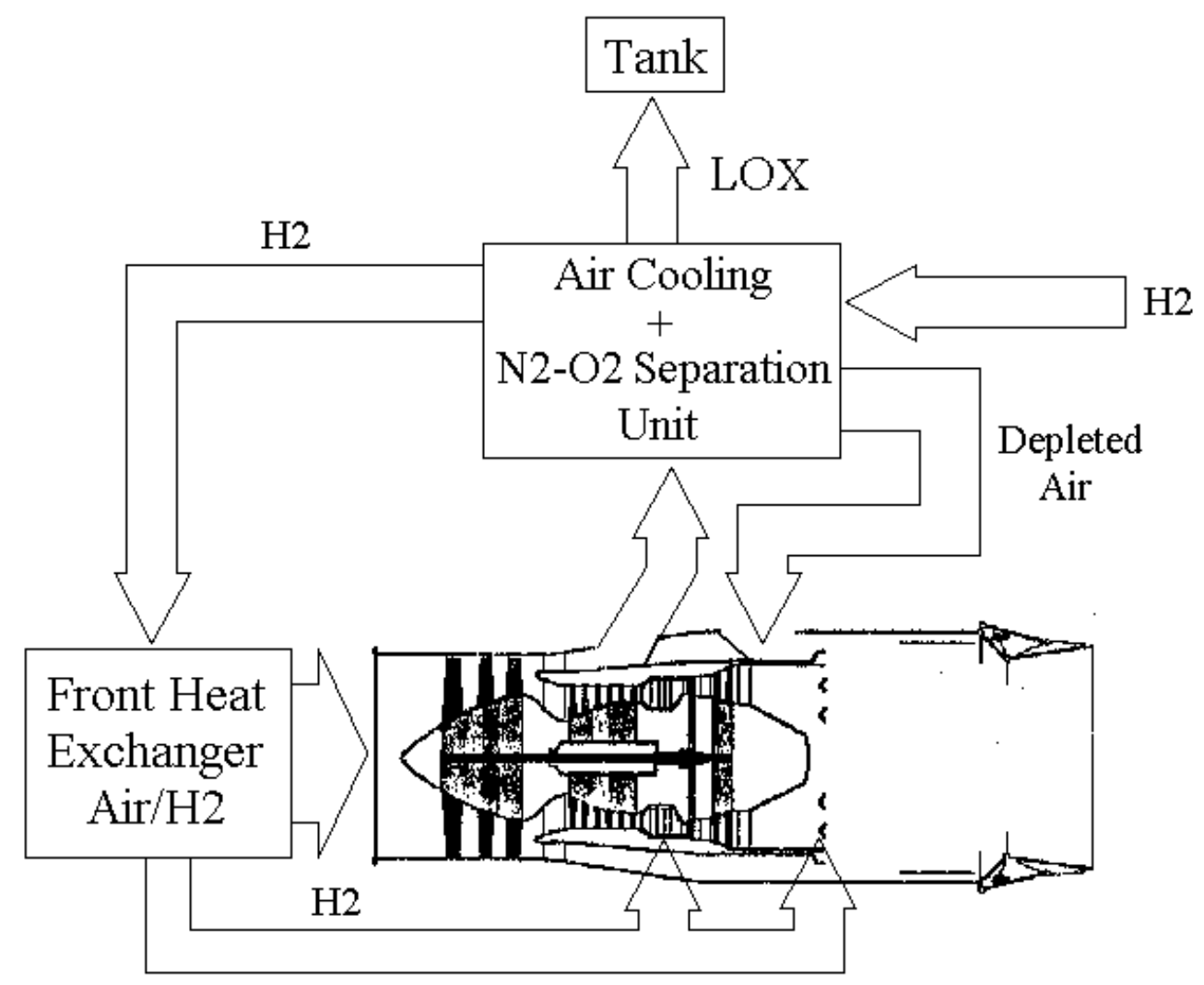

Figure 2: Integrated propulsion LOX collection engine

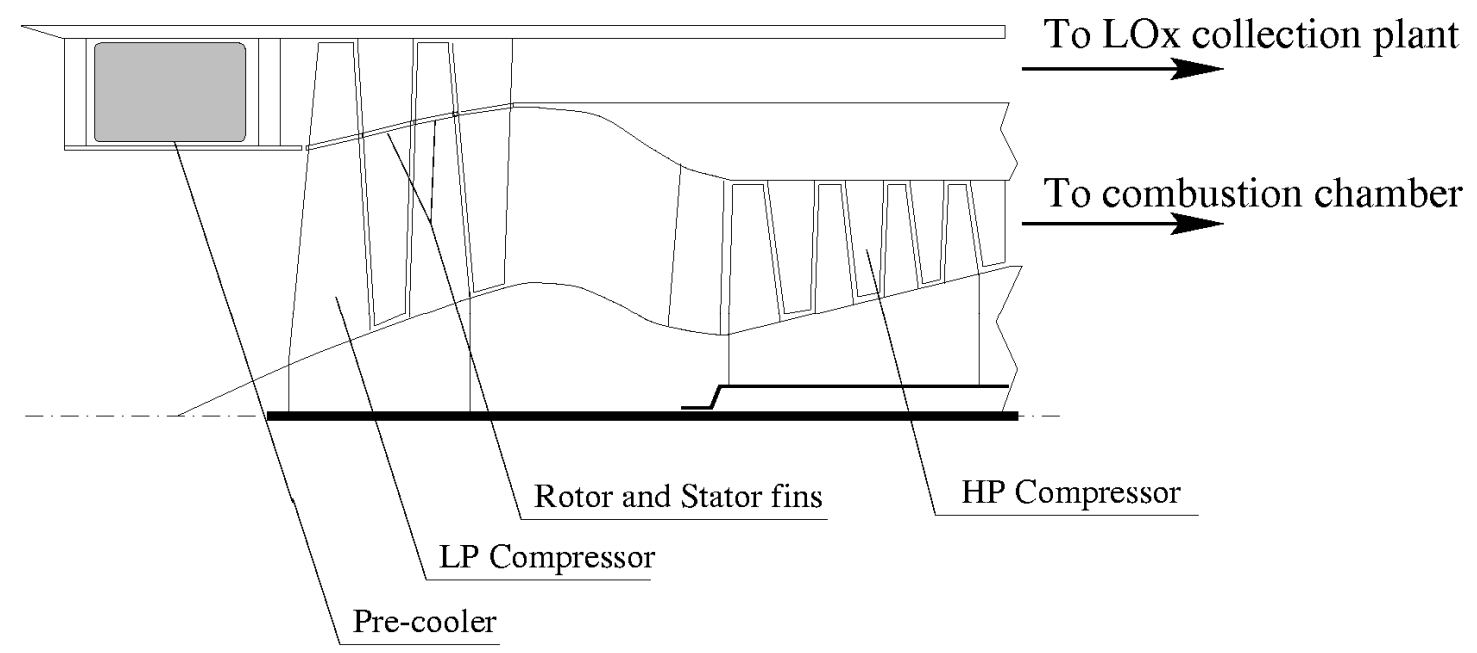

Figure 3: The ring pre-cooler system

Corresp. author : D.Bizzarri, Université libre de Bruxelles CP165/43,Dpt of fluid Mechanics, Avenue F.Roosevelt 50, 1050 Brussels, Belgium. Tel + 32650 6654. Fax + 326502710 . Email Didier.Bizzarri@ulb.ac.be 


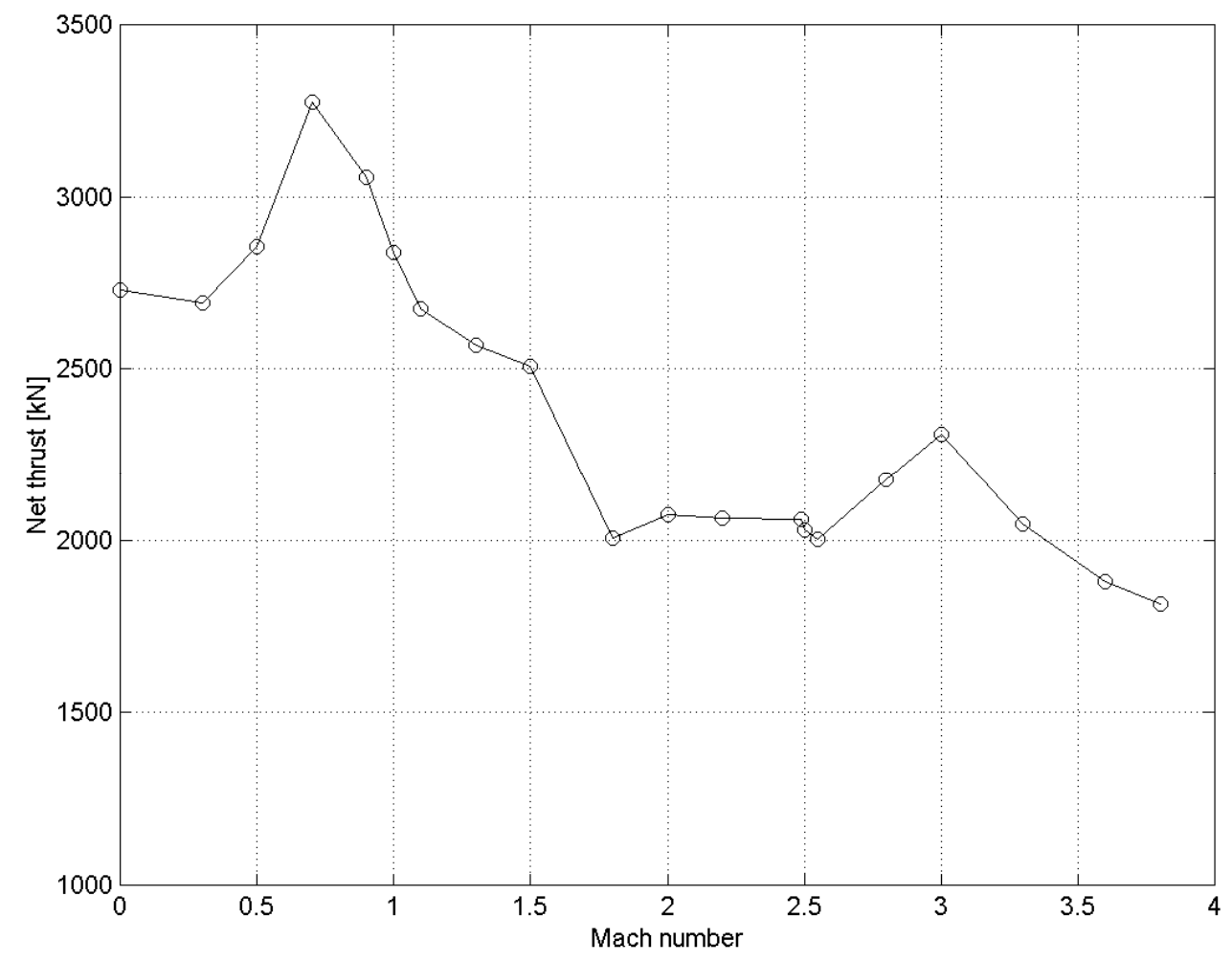

Figure 4: Maximum thrust capability (Turbofan engine with ring pre-cooler

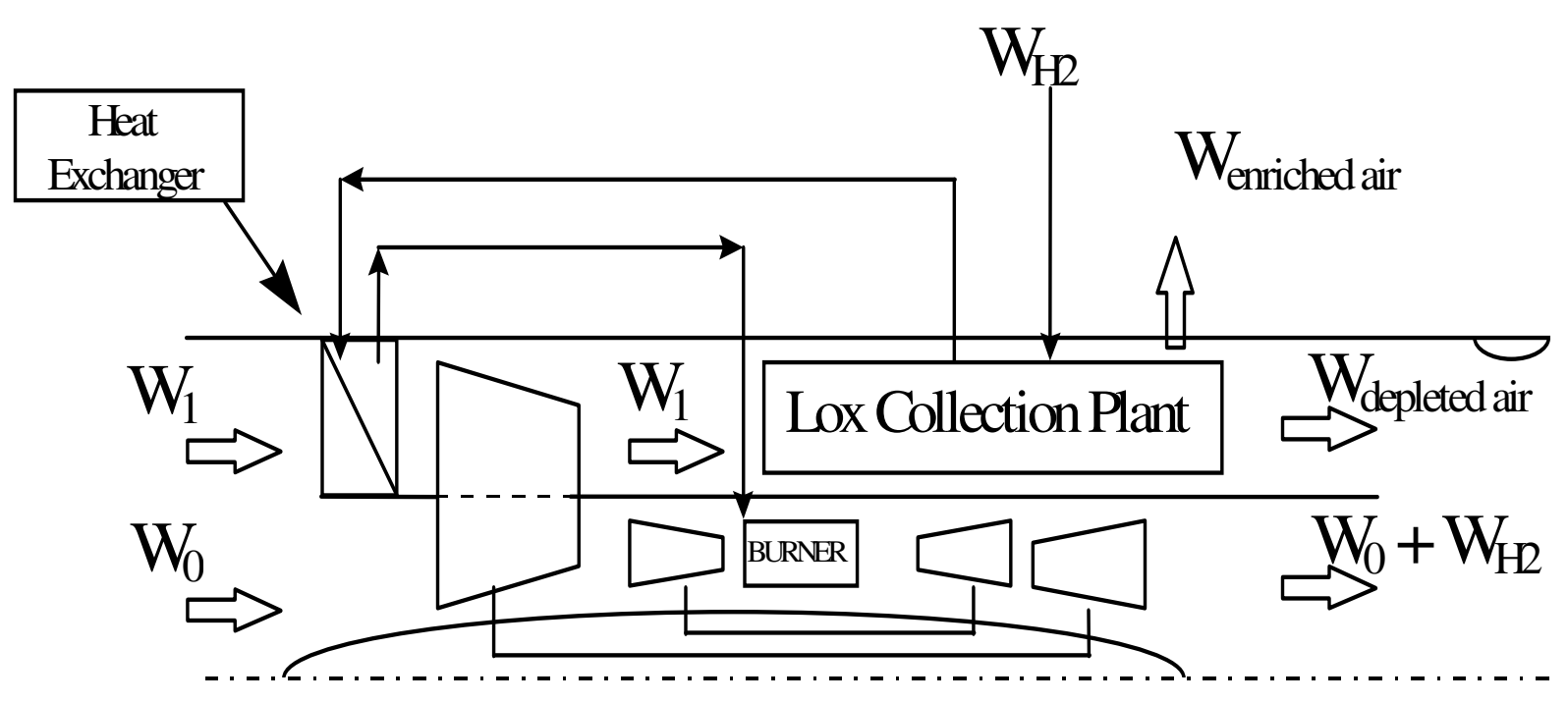

Figure 5: Integrated LCP-engine architecture

Corresp. author : D.Bizzarri, Université libre de Bruxelles CP165/43,Dpt of fluid Mechanics, Avenue F.Roosevelt 50, 1050 Brussels, Belgium. Tel + 32650 6654. Fax + 326502710 . Email Didier.Bizzarri@ulb.ac.be 


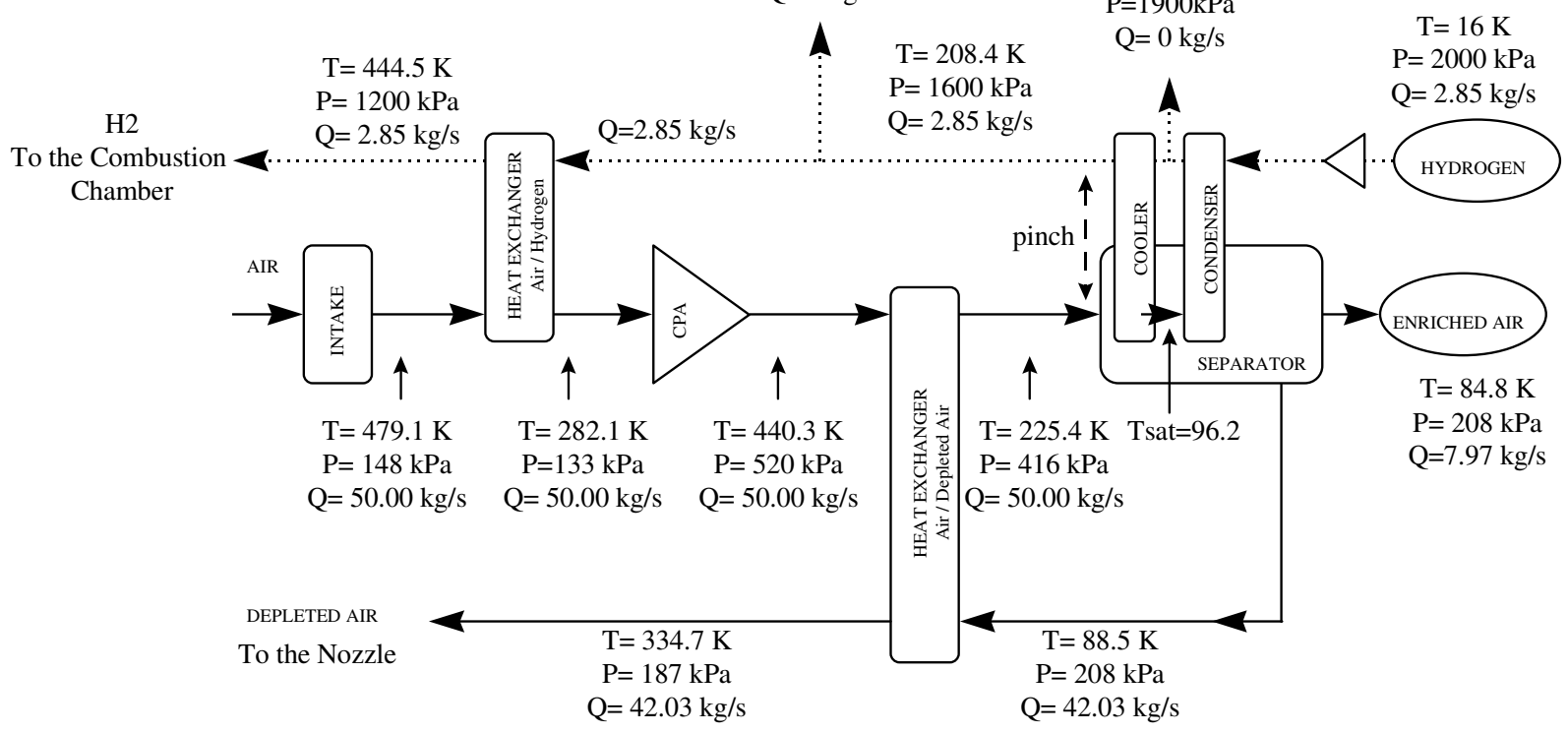

Figure 6: Ring heat exchanger configuration, LCP main parameters
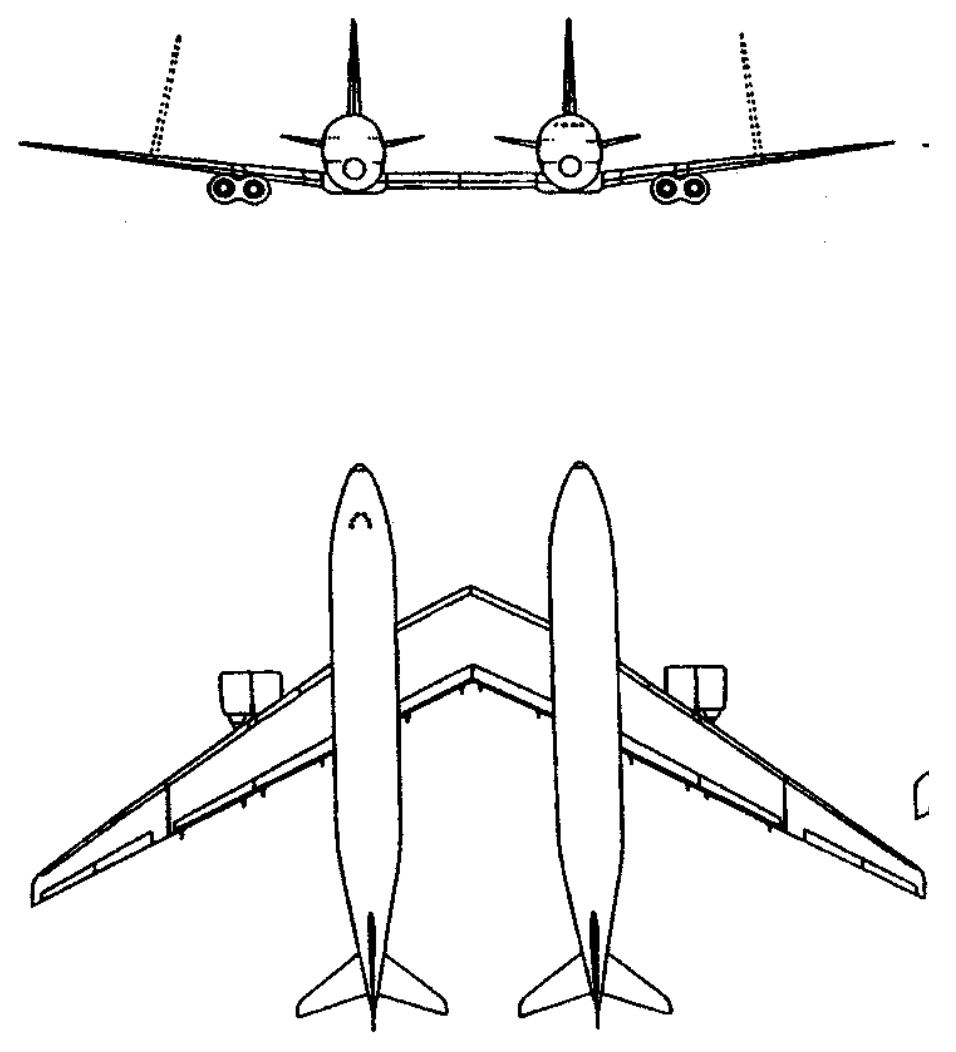

Figure 7 A twin-fuselage design

Corresp. author : D.Bizzarri, Université libre de Bruxelles CP165/43,Dpt of fluid Mechanics, Avenue F.Roosevelt 50, 1050 Brussels, Belgium. Tel + 32650 6654. Fax + 326502710 . 


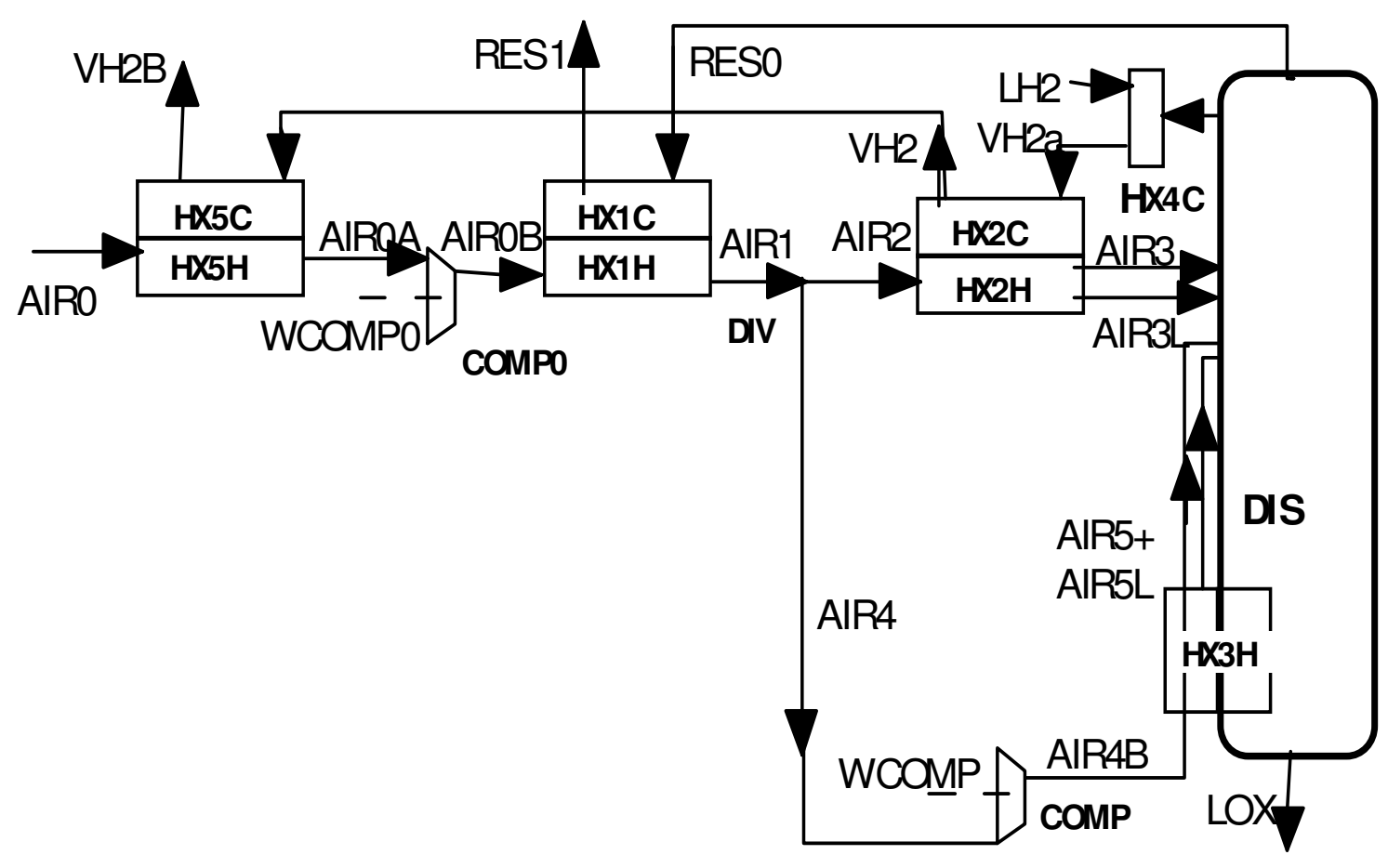

Figure 8: Flowsheet for the supersonic case

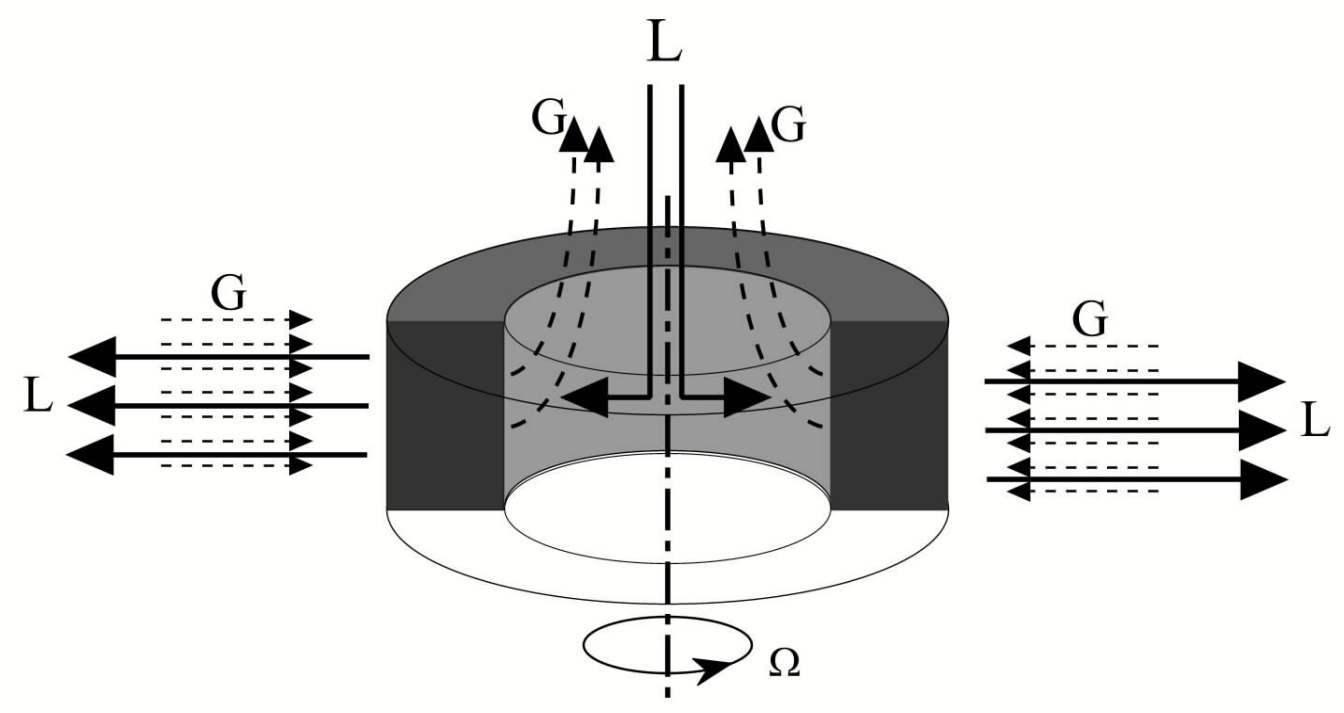

Figure 9: mass flows in a rotating vapor-liquid contactor. The porous separator bed is shown as a cut-out. Liquid goes radially outside and gas travels radially inside.

Corresp. author : D.Bizzarri, Université libre de Bruxelles CP165/43,Dpt of fluid Mechanics, Avenue F.Roosevelt 50, 1050 Brussels, Belgium. Tel + 32650 6654. Fax + 326502710 . Email Didier.Bizzarri@ulb.ac.be 


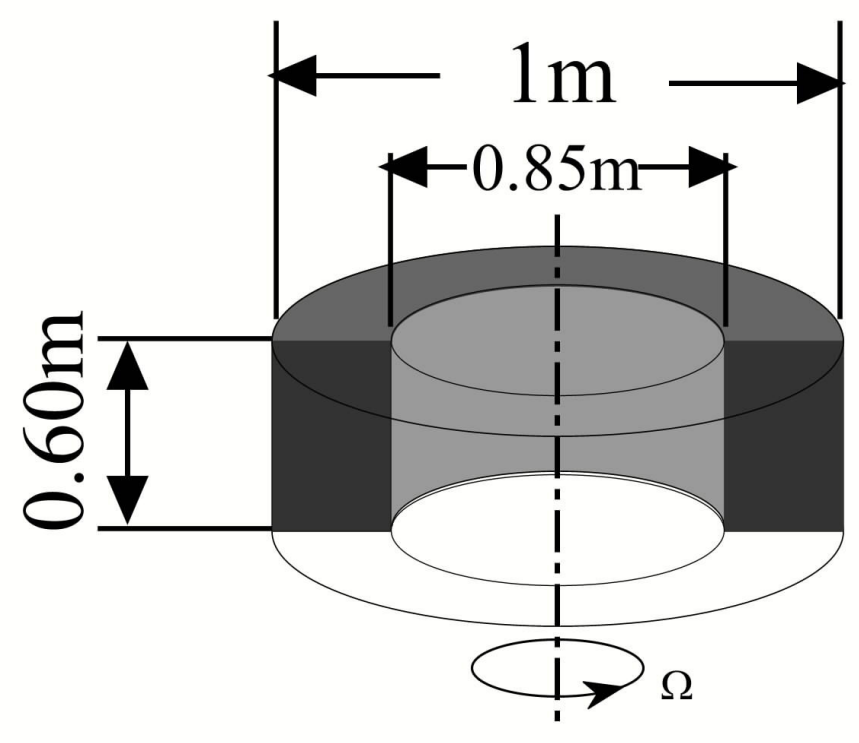

Figure 10: bed dimensions computed for the base separation unit as defined in [10] .

Embodying the bed in a rotating casing could increase the diameter to $1 \mathrm{~m} 20$. The weight of the bed is about $100 \mathrm{~kg}$. The weight of the enclosed unit would be several times higher due to size and necessity to use stainless steel ( $\mathrm{Al}$ is usually hazardous, but safe design may be possible). 3 units are required for the subsonic $1^{\text {st }}$ stage concept.

$\% \% \% \% \% \% \% \% \% \% \% \% \% \% \% \% \% \% \% \% \% \% \% \% \% \% \% \% \% \% \% \% \% \% \% \% \% \% \% \% \% \%$ $\% \% \% \% \% \% \% \%$

TABLES

$\% \% \% \% \% \% \% \% \% \% \% \% \% \% \% \% \% \% \% \% \% \% \% \% \% \% \% \% \% \% \% \% \% \% \% \% \% \% \% \% \% \% \% \% \%$ $\% \% \% \% \% \% \% \% \%$

\begin{tabular}{||l|l|l|l||}
\hline \multicolumn{1}{|c|}{$\begin{array}{c}\text { Sizing } \\
\text { Parameter }\end{array}$} & \multicolumn{1}{|c|}{$\begin{array}{c}\text { Cox }= \\
\mathbf{9 5 \%}\end{array}$} & $\begin{array}{c}\text { Cox }= \\
\mathbf{9 2 \%}\end{array}$ & \multicolumn{1}{|c|}{$\begin{array}{c}\text { Cox }= \\
\mathbf{9 0 \%}\end{array}$} \\
\hline TOGW $(\mathrm{t})$ & 333.4 & 353.0 & 369.2 \\
\hline $\mathrm{Wdry}_{1}(\mathrm{t})$ & 185.0 & 195.4 & 203.9 \\
\hline Cruise $(\mathrm{s})$ & 2279 & 2409 & 2507 \\
\hline$\tau_{\mathrm{o}}(-)$ & 0.0523 & 0.0510 & 0.0500 \\
\hline $\mathrm{W}_{\mathrm{LH}_{2,1}(\mathrm{t})}$ & 90.6 & 96.9 & 102.2 \\
\hline $\mathrm{Vppl}_{1}\left(\mathrm{~m}^{3}\right)$ & 1264 & 1352 & 1426 \\
\hline $\mathrm{LOGW}_{2}(\mathrm{t})$ & 178.1 & 189.2 & 198.5 \\
\hline $\mathrm{Wdry}_{2}(\mathrm{t})$ & 30.1 & 31.7 & 33.0 \\
\hline$\tau_{2}(-)$ & 0.0764 & 0.0743 & 0.0727 \\
\hline $\mathrm{W}_{\mathrm{LOX}_{2}}(\mathrm{t})$ & 122.1 & 130.3 & 137.2 \\
\hline \hline
\end{tabular}

Table 1: (Indices 0,1 and 2 refer respectively to the whole vehicle, the $1^{\text {st }}$ stage and the $2^{\text {nd }}$ stage)

\section{NB : Some variables are not defined in the text}

Corresp. author : D.Bizzarri, Université libre de Bruxelles CP165/43,Dpt of fluid Mechanics, Avenue F.Roosevelt 50, 1050 Brussels, Belgium. Tel + 32650 6654. Fax + 326502710 . Email Didier.Bizzarri@ulb.ac.be 


\begin{tabular}{|c|c|c|c|c|}
\hline Concept & $\begin{array}{c}\eta_{\text {sep }} \\
\text { range }\end{array}$ & $\begin{array}{c}\text { Min. CR } \\
\text { range }\end{array}$ & $\begin{array}{c}\text { required } \\
\text { LEA } \\
\text { production }\end{array}$ & Cox range \\
\cline { 1 - 4 } $\begin{array}{c}\text { Supersonic } \\
\text { staging }\end{array}$ & $65-70 \%$ & $2.4-2.8$ & $65 \mathrm{~kg} / \mathrm{s}$ & $85-95 \%$ \\
\cline { 1 - 1 } $\begin{array}{c}\text { Subsonic } \\
\text { staging }\end{array}$ & $65-70 \%$ & $1.5-2$ & $9 \mathrm{~kg} / \mathrm{s}$ & $85-95 \%$ \\
\cline { 1 - 3 } & & & &
\end{tabular}

Table 2: parameters of the LOX/LEA Collection Plant for both supersonic and subsonic $1^{\text {st }}$ stage concepts

Corresp. author : D.Bizzarri, Université libre de Bruxelles CP165/43,Dpt of fluid Mechanics, Avenue F.Roosevelt 50, 1050 Brussels, Belgium. Tel + 32650 6654. Fax + 326502710 . Email Didier.Bizzarri@ulb.ac.be 